\title{
Self-awareness and access to material rated as self-descriptive or nondescriptive
}

\author{
JOHN H. MUELLER \\ University of Missouri, Columbia, Missouri 65211
}

\begin{abstract}
Subjects selected as high or low in self-consciousness rated trait adjectives for selfdescriptiveness, meaningfulness, and familiarity, and then were given an unannounced recall test. High self-aware subjects were clearly faster at making self-descriptiveness judgments, relative to low self-aware subjects, a difference that was not significant for meaningfulness or familiarity decisions. These results support the hypothesis that subjects who are more selfaware access personal information more rapidly than less self-aware subjects. There were no self-awareness differences in total recall or the organization of recall, apparently because three successive encoding tasks eliminated such differences. Self-reference decisions were faster than nonself decisions for high self-aware subjects, but slower for less self-aware subjects.
\end{abstract}

Recent research has established self-referencing of experiences as a particularly productive mnemonic strategy (cf. Greenwald, 1981; Rogers, 1981). For example, Kuiper and Rogers (1979) found that memory for trait adjectives was enhanced by a study task that required subjects to judge whether the word "describes you," relative to deciding whether it describes some other person, or whether it is a synonym of some other word. Further, descriptive items are recalled better than nondescriptive items. It appears that one's representation of the self-concept in memory aids retention by the general process of relating incoming information to some preexisting memory structure (see also Bower \& Gilligan, 1979; Keenan \& Baillet, 1980). One question addressed by the present study was whether this general facilitation due to self-referencing would be more apparent for some subjects than for others. Specifically, do subjects who are likely to attend to their internal processes perform better than less self-aware subjects when self-comparisons are imposed by an external task?

The Self-Consciousness Questionnaire (SCQ) can be used to identify a subject's level of self-awareness (Fenigstein, Scheier, \& Buss, 1975; see also Buss, 1980). The SCQ consists of 23 items answered on a $1-5$ rating scale and yields three scores: private self-consciousness (SC), public SC, and social anxiety. A person high on the private $\mathrm{SC}$ factor is said to be self-reflective, introspective, and likely to examine moods, motives, and fantasies. People high on public SC are concerned with the impression they make on others, and people high on social anxiety become aroused in the presence of others.

Evidence that individual differences in self-awareness, as measured by the SCQ, affect self-comparisons has

Requests for reprints should be sent to J. Mueller, Psychology Department, 210 McAlester Hall, University of Missouri, Columbia, Missouri 65211. Helpful comments were provided on an earlier draft by Robert Arkin, Richard Petty, Mike Ross, and Marty Heesacker. appeared in some recent studies. Turner (1978) found that decisions about the self-descriptiveness of trait terms were made faster by subjects who scored high on the private SC scale. However, this was true only for socially undesirable traits, which Turner suggested indicated that both high and low self-aware subjects had ready access to positive information, whereas only those high in self-awareness had immediate access to their negative features. Turner (1980) found that subjects high in private SC recalled more trait adjectives than low-SC subjects, as if habitual self-focusers more spontaneously utilize the beneficial self-reference strategy. Hull and Levy (1979) likewise observed greater recall by high private SC subjects, and Lord (1980) also observed better recall of self-referent words relative to other-referent words by subjects who scored high on a different self-monitoring scale. These results suggest two effects. First, subjects who regularly self-focus and monitor their mental processes access personal information quite rapidly. Second, personal information is remembered better by subjects who are generally attentive to their cognitive processes.

The present experiment examined this issue further, but using a procedure in which subjects who made self-reference decisions also rated the same items on meaningfulness and familiarity. This manipulation has direct relevance to a prediction made by Zajonc (1980). In identifying self-reference as an emotional judgment, Zajonc argued that such decisions should be made more rapidly than semantic or nonemotional decisions. There is evidence in accord with this expectation. For example, Keenan and Baillet (1980) found that self-reference decisions were made more rapidly than decisions about other people and decisions about semantic content. However, some studies have actually found self-reference to be slower than other encoding decisions (e.g., Cacioppo \& Petty, 1981; Mueller \& Courtois, 1980). Given such mixed results, further research seems warranted, 
especially in view of the possible role of individual differences in self-awareness, and the possible interaction of level of self-awareness with the emotional content of the material (Turner, 1978).

Thus, the present study examined self-reference and nonself decisions about material that varied in social desirability and compared subjects preselected as either high or low in self-awareness. We specifically wanted to determine whether the more self-aware subjects were faster in general, or only for certain material or certain decisions. We also wanted to determine whether the relative decision speeds varied for self- and nonself judgments, and whether this pattern was qualified by level of SC. Finally, the relative level of incidental recall associated with each level of SC was of interest.

\section{METHOD}

\section{Subjects}

The SCQ was administered to a large pool of introductory psychology students. Sixteen subjects, eight males and eight females, were randomly recruited from the upper end of the distribution of private SC scores; all had private SC scores of at least 31 (mean $=33.4)$. Similarly, 16 low scorers were selected, eight males and eight females, all with private SC scores below $20($ mean $=16.3)$.

\section{Materials}

The items rated were 100 words selected from the 200 most meaningful trait adjectives in the Anderson (1968) norms. Fifty words had likability ratings above 4.50 , and 50 had likability ratings below 1.64 .

\section{Procedure}

In the rating phase of the study, each word was rated three times, once each for self-descriptiveness, meaningfulness, and familiarity. All three dimensions were judged consecutively for one word before the next word was presented, but the order in which the three dimensions were rated was randomly varied over words. Each subject saw the 100 adjectives in a unique random order. The words were presented one at a time on a CRT screen controlled by a PDP-11/34 computer. The word, the dimension to be rated, and the 8-point scale with its anchors all appeared on the screen together. The subject indicated a response, then the screen was blanked before the word and the next dimension appeared, and so forth. Subjects responded to each word by pressing one of the number keys (1-8) at the top of the keyboard. Subjects were instructed to respond as quickly as possible within the constraints of accuracy. The experimenter was not present during this phase, to reduce the likelihood of impression management.

The unannounced recall test followed the rating phase after an interval of about $10 \mathrm{~min}$. Subjects had $10 \mathrm{~min}$ to write down as many of the 100 words as possible, in any order.

\section{RESULTS}

\section{Ratings of Self-Descriptiveness}

For purposes of analysis, words rated 1-4 were considered nondescriptive and those rated 5-8 were considered self-descriptive, to obtain a sufficient number of nonzero entries of each type. There was a significant Descriptiveness by Likability interaction $[F(1,30)=$
399.47], as more likable words were rated descriptive (mean $=44.09)$ than nondescriptive $($ mean $=5.91)$, whereas more unlikable words were rated nondescriptive $($ mean $=40.47)$ than descriptive (mean $=9.53)$. The absence of a significant SC by Descriptiveness by Likability interaction $(\mathrm{F}<1)$ indicates this pattern occurred for both high- and low-SC subjects.

\section{Rating Latencies}

The average decision speed for the ratings on each of the three dimensions is shown in Table 1 . These latencies were analyzed in a 2 (SC) by 2 (likability) by 2 (descriptiveness) by 3 (judgment: self, meaningfulness, familiarity) mixed factorial, with the last three factors within subjects.

There are some reasons to expect self-reference decisions to be faster than other decisions (cf. Zajonc, 1980), but this has not always been found (e.g., Cacioppo $\&$ Petty, 1981; Mueller \& Courtois, 1980). This analysis revealed a main effect for type of judgment $[F(2,60)=$ $6.55, \mathrm{p}<.01$ ], with familiarity judgments being made faster than either meaningfulness or self-descriptiveness judgments (means $=3,235,3,548$, and $3,579 \mathrm{msec}$, respectively). The critical SC by Judgment interaction was also significant $[\mathrm{F}(2,60)=3.50, \mathrm{p}<.05]$. This interaction reveals that low-SC subjects were 3\%-4\% slower than high-SC subjects for meaningfulness decisions (means $=3,615$ and $3,481 \mathrm{msec}$ ) and familiarity decisions (means $=3,289$ and $3,181 \mathrm{msec}$ ), but over $18 \%$ slower for self-descriptiveness decisions (means = 3,880 and $3,278 \mathrm{msec}$ ). Post hoc comparisons revealed that the SC difference was not significant for meaningfulness or familiarity judgments.

A marginally significant SC by Descriptiveness by Judgment interaction $[F(2,60)=2.97, p<.06]$ indicated that the pattern just described held for both descriptive and nondescriptive items in regard to meaningfulness and self-descriptiveness judgments, but for familiarity the high-SC subjects were slower on non-

Table 1

Rating Latencies (in Milliseconds) by Likability, Descriptiveness, and Judgment for Subjects Scoring High and Low on Private Self-Consciousness (SC)

\begin{tabular}{lcccccccc}
\hline & \multicolumn{3}{c}{ Likable } & & \multicolumn{3}{c}{ Unlikable } \\
\cline { 2 - 4 } \cline { 5 - 8 } \cline { 5 - 8 } & D & ND & All & D & ND & All \\
\hline Self Latency & 3075 & 3352 & 3214 & 3411 & 3273 & 3342 \\
Meaning Latency & 3067 & 3708 & 3388 & 3822 & 3327 & 3574 \\
Familiar Latency & 2987 & 3642 & 3315 & 2887 & 3209 & 3048 \\
& \multicolumn{5}{c}{ Low Private SC } \\
Self Latency & 3586 & 3946 & 3766 & 4317 & 3670 & 3993 \\
Meaning Latency & 3367 & 3853 & 3610 & 3608 & 3630 & 3619 \\
Familiar Latency & 3167 & 3155 & 3161 & 3580 & 3254 & 3417 \\
\hline
\end{tabular}

Note-D refers to words rated as self-descriptive, and ND refers to nondescriptive adjectives. 
descriptive items and faster only on descriptive items. There was also a marginal SC by Likability by Judgment interaction $[\mathrm{F}(2,60)=2.55, \mathrm{p}<.09]$. This interaction indicated that high-SC subjects were faster than low-SC subjects for all judgments involving unlikable items and for meaningfulness and self-descriptiveness judgments of likable words, but high-SC subjects were slower for familiarity judgments of likable words.

In summary, considering all three interactions, highSC subjects generally had faster reaction times for all three judgments. The advantage was greatest for selfreference decisions, and reversed for familiarity judgments of likable or nondescriptive items. There was no evidence that the faster access by high self-awareness subjects was limited to the socially undesirable items, as had been found by Turner (1978).

\section{Recall}

Probability of recall was computed by dividing the number of words recalled from each of the four subtypes (descriptive-likable, nondescriptive-likable, descriptive-unlikable, nondescriptive-unlikable) by the number of items of each type as determined in the rating phase. This adjusts for a variable number of items of each type across subjects, so that differential recall would not be attributable to unequal opportunities (cf. Kuiper \& Rogers, 1979).

Table 2 summarizes the recall data. Likable words were recalled slightly better than unlikable words (means $=.23$ and .19), but the effect was not significant $(\mathrm{F}=1.18)$. Self-descriptive words were not recalled any better than nondescriptive items (means $=.21$ and .21 ), and the Descriptiveness by .Likability interaction was nonsignificant $(F<1)$. There was no difference $(\mathrm{F}<1)$ for high and low SC (means $=.20$ and .21 ), nor were there any interactions involving level of SC $(\mathrm{Fs}<1)$.

It is possible that amount recalled might not be sensitive to SC level, whereas the organization of recall would be. That is, would high-SC subjects show a greater tendency to group words together in recall on the basis of descriptiveness? To answer this question, clustering analyses were performed (adjusted ratio of clustering; Roenker, Thompson, \& Brown, 1971) first in terms of organization in recall by likable and unlik-

Table 2

Probability of Recall by Likability, Descriptiveness, and Level of Private Self-Consciousness (SC)

\begin{tabular}{lcccccccc}
\hline & \multicolumn{3}{c}{ Likable } & & \multicolumn{3}{c}{ Unlikable } \\
\cline { 2 - 4 } \cline { 7 - 8 } & D & ND & All & & D & ND & All \\
\hline High Private SC & .24 & .22 & .23 & .16 & .19 & .18 \\
Low Private SC & .21 & .24 & .23 & .22 & .18 & .20 \\
All Subjects & .22 & .23 & .23 & .19 & .18 & .19 \\
\hline
\end{tabular}

Note-D refers to words rated as self-descriptive, and ND refers to nondescriptive adjectives. able items, then by descriptive and nondescriptive items, and finally, by all four subtypes of likability and descriptiveness. There were no differences due to level of selfawareness for any of these three classification schemes (ts $<1)$.

\section{DISCUSSION}

These data support the primary hypothesis of this study: Compared with high-SC subjects, low-SC subjects required more time to make self-reference decisions, as if this information was less accessible for low-SC subjects. Low-SC subjects were also slower at making decisions about meaningfulness, but the difference between high- and low-SC subjects was not significant. Similarly, the SC difference was not clear-cut for the familiarity decision. That the effect of level of self-awareness was specific to self-reference decisions and not as apparent for nonself judgments seems quite in accord with the hypothesis that self-reflective habits are assessed by the SCQ and that these affect the processing of personal information but have less impact on nonpersonal decisions.

Retention of the rated material did not indicate any differences due to SC level (a result that was also obtained in a pilot study). Although self-referencing did reveal some differences in speed of access to personally relevant information, once that access was achieved the beneficial memorial results of such processing were also obtained, independent of SC level. Latency differences in the absence of retention differences have been reported in other studies of self-reference (for example, Breckler \& Greenwald, Note 1). Given that the "study" phase here also involved two other useful mnemonic decisions for each word, it seems most likely that other shortcomings in memory strength, such as differences due to self-awareness, were essentially overcome.

Finally, returning to the expectation that self-reference decisions are made faster than other decisions (Zajonc, 1980), the results of the present study suggest that whether self-reference decisions are slower or faster than semantic decisions depends on the subject's self-awareness. For high-SC subjects, self-reference decisions are faster than meaningfulness decisions, but the reverse is true for low-SC subjects. Of course, it is coneeivable that for emotional content defined more generally, access speed will be faster for emotional judgments than for nonemotional decisions for all subjects. When emotionality is defined specifically in terms of self-reference though, this generalization may require qualification.

\section{REFERENCE NOTE}

1. Breckler, S. J., \& Greenwald, A. G. Favorable self-referent judgments are made faster than non-favorable ones. Paper presented at the Midwestern Psychological Association meetings, Detroit, 1981.

\section{REFERENCES}

Anderson, N. H. Likableness ratings of 555 personality-trait words. Journal of Personality and Social Psychology, 1968, 9, 272-279.

Bower, G. H., \& Gilligan, S. G. Remembering information about one's self. Journal of Research in Personality, 1979, $13,420-432$.

Buss, A. H. Self-consciousness and social anxiety. San Francisco: Freeman, 1980.

Cacioppo, J. T., \& Petty, R. E. Electromyographic specificity during covert information processing. Psychophysiology, 1981, 18, 518-523.

Fenigstein, A., Scheier, M. F., \& Buss, A. H. Public and 
private self-consciousness: Assessment and theory. Journal of Clinical and Consulting Psychology, 1975, 43, 522-527.

Greenwald, A. Self and memory. In G. H. Bower (Ed.), Psychology of learning and motivation (Vol. 15). New York: Academic Press, 1981.

Hull, J. G., \& LEvy, A. S. The organizational functions of the self: An alternative to the Duval and Wicklund model of selfawareness. Journal of Personality and Social Psychology, 1979, 37, 756-768.

Keenan, J. M., \& Baillet, S. D. Memory for personally and socially significant events. In R. S. Nickerson (Ed.), Attention and performance (Vol. 8). Hillsdale, N.J: Erlbaum, 1980.

Kuiper, N. A., \& Rogers, T. B. Encoding of personal information: Self-other differences. Journal of Personality and Social Psychology, 1979, 37, 499-514.

LoRD, C. G. Schemas and images as memory aids: Two modes of processing social information. Journal of Personality and Social Psychology, 1980, 38, 257-269.

Mueller, J. H., \& Courtois, M. R. Retention of self-descriptive and nondescriptive words as a function of test anxiety level. Motivation and Emotion, 1980, 4, 229-237.

Rogers, T. B. A model of the self as an aspect of the human information processing system. In N. Cantor \& J. F. Kihlstrom (Eds.), Personality, cognition, and social interaction. Hillsdale, N.J: Erlbaum, 1981.

Roenker, D. L., Thompson, C. P., \& Brown, S. C. Comparison of measures for the estimation of clustering in free recall. Psychological Bulletin, 1971, 76, 45-48.

TURNer, R. G. Self-consciousness and speed of processing of self-relevant information. Personality and Social Psychology Bulletin, 1978, 4, 456-460.

TURne R, R. G. Self-consciousness and memory of trait terms. Personality and Social Psychology Bulletin, 1980, 6, 273-277.

ZAJONC, R. B. Feeling and thinking: Preferences need no inferences. American Psychologist, 1980, 35, 151-175.

(Received for publication March 8, 1982.) 